\title{
Risks of the Durability of Large-Panel Buildings Elevations in Reference to the Conclusions from Technical Conditions Audits
}

\author{
Piotr Knyziak ${ }^{1, *}$, Janusz R. Krentowski ${ }^{2}$ and Piotr Bieranowski ${ }^{3}$ \\ ${ }^{1}$ Warsaw University of Technology, Al. Armii Ludowej 16, 00-637 Warsaw, Poland \\ ${ }^{2}$ Bialystok University of Technology, Wiejska str. 45, 15-351 Bialystok, Poland \\ ${ }^{3}$ University of Warmia and Mazury in Olsztyn, Oczapowskiego str. 11, 10-719 Olsztyn, Poland
}

\begin{abstract}
In article the problem of durability of elevations of large-panel technology buildings is analyzed. In Poland this is a serious technical issue because it has an impact on the whole country. Heat loss through infiltration, the possibility of mold growth and general breakdowns are also reasons for increasing user discomfort. In article the results of the diagnostics presented in the literature and the authors' analysis and diagnostic results are presented. Article also presents conclusions regarding to the durability of applied insulation systems ETICS and the need to strengthening the layers connections of the facade panels.
\end{abstract}

\section{Introduction}

Building prefabrication in Poland has a bad reputation, especially in the area of residential buildings. From one side it is result of the real mistakes in designing and manufacturing process, on the other side such point of view was formed in newspapers articles where the problem of defects has been highlighted and maximizing.

In buildings made of precast concrete plates the influence of unfavourable factors can not disclose for a very long time. Prefabricated buildings build in Poland in XX century are especially sensitive in regard to the layered structure of cladding panels of which were made external walls. They consist of a structural layer, an insulating layer made of polystyrene or mineral wool with varying thicknesses and a finishing layer. Thickness of the designed layers were different in different systems and they took into account the climatic zones, the number of storeys and the type of connecting elements. The technical condition of connections of these layers is the main problem, because often to achieve savings ordinary steel were used in them instead of stainless steel.

Both insulation and textured finishing layers were fixed to the structural panel by means of fasteners specified as "hangers" (Figure 1), made of steel bars. The effectiveness of the connection of the two concrete layers determines the durability of such external wall.

In the $1980 \mathrm{~s}$, as a result of research carried out on the Building Research Institute in Warsaw, hangers made of H13N4G9 steel were recommended. It was found that connectors made of St3SX steel had actually been used. Moreover, the presence of galvanized bars of StOS steel was confirmed [1]. There were also errors in the layout, number and diameters

* Corresponding author: p.knyziak@il.pw.edu.pl 
of the hangers used. In addition, it was found that the thickness of concrete in the façade layers often exceeded the designed values, resulting in both an increase in the weight and a reduction in the thickness of the thermal insulation layer. Consequently, it resulted in a reduction in the thermal insulation of the shielding wall and an increase in the stresses in the hangers due to both the heavier load of the façade layer and the thermal deformation of the façade panel exposed to direct weather and temperature stress. In an aggressive environment, in case of leakage of the façade layer, rain water, containing dissolved substances accelerating the corrosion process of the steel hangers, penetrates into the insulation space.
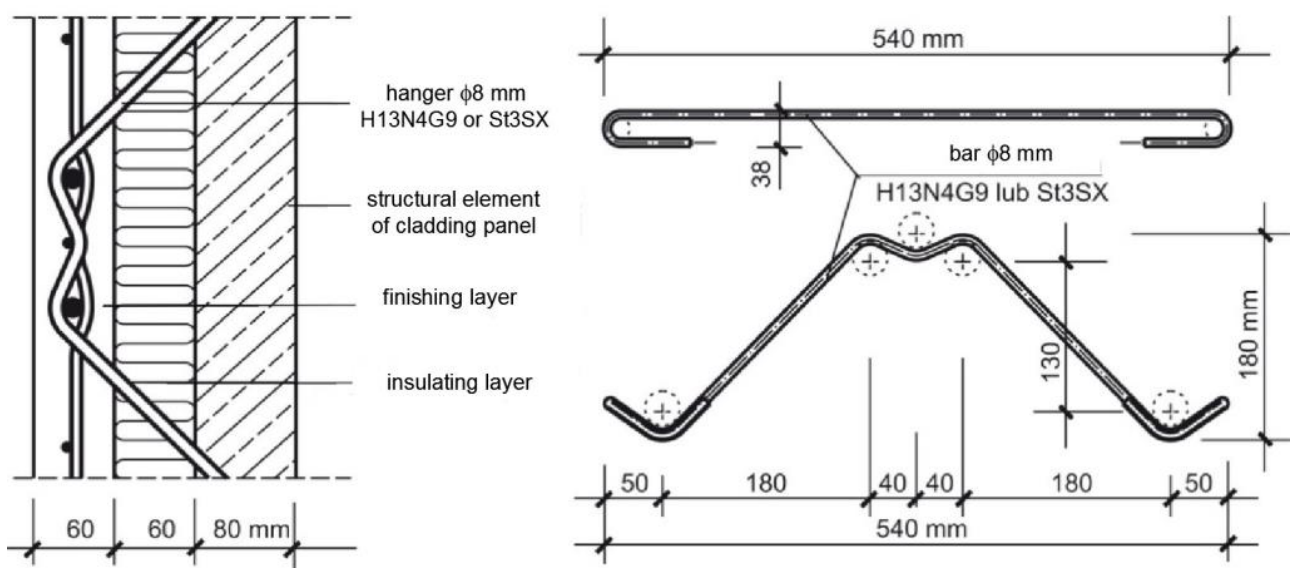

Fig 1. Construction of a connection of prefabricated wall elements in a Wk-70 system

Nowadays the high thermal conductivity of panels and connections leak causing moisture of precast elements are very important problems (Figure 2). Often wetting of the structure resulting from the leakage of connection is a stimulator of many degradation processes. They have a significant impact on the condition of not only individual panels or components, but the entire building. The negative effects of moisture have an influence on the health of residents by supporting the development of fungi and molds.
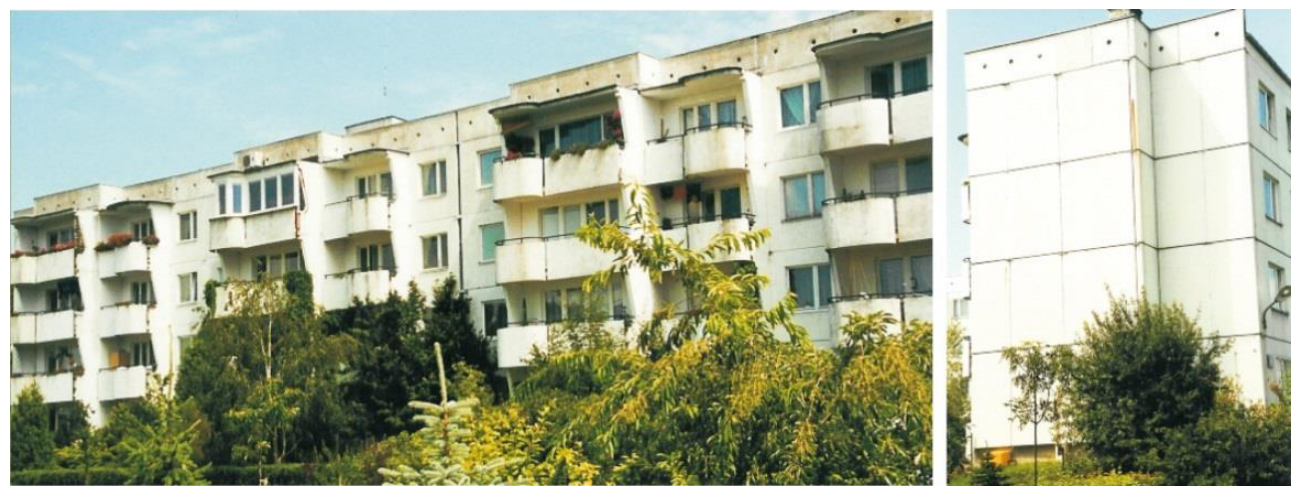

Fig. 2. Building façades in Wk-70 technology, Warsaw (photos by Janusz Krentowski)

It can be noted that after the executed thermorenovations of large-panel buildings [2], increased heat loss through contact zones of windows' frames and walls, prefabricated facade panels connections/joints, loggias' and balconies' bonding zones and plinth zones 
may be observed. Such repairs can be regarded as barely sufficient, but the results of their execution do not comply with the economic requirements of thermal protection. In the further use of buildings, the elimination of thermal bridges still remains a major problem.

Housing co-operatives in Poland, using state financial aid launched in 1982, have warmed/insulated many buildings or at least their gable walls. Up to 1997, it was financed from subsidies on housing cooperatives for the removal of technological defects. Unfortunately, especially in the first years, the insulation thickness was $2 \div 3$-fold smaller than the current requirements of buildings thermal protection. In addition, in some cases a heavy dry method or insulation of fiber-cement boards was used, which did not allow for the addition of another insulation layer. As a consequence of a low thickness of styrofoam or mineral wool used in the first layers of insulation, many of the evaluated buildings had to be insulated repeatedly. At present, the typical insulation thickness is $16 \mathrm{~cm}$ of styrofoam.

\section{Risks of the elevation durability indicated in the literature}

Problems with the elements forming the facade of the large-panel buildings have been analyzed by many authors.

The research on panel layer fasteners were carried out on a wide scale around 1985 at the Silesian Technical University in Gliwice [3]. Hangers and pins from the current production of prefabrication factories made of St3SX steel were used for the tests. As a result of the study, images of the deformations of the hangers and displacements of the façade layer were obtained. What was important, it was found that during subsequent phases of work, the system connecting the wall-supporting plate with the façade layer indicates the failure by large displacements resulting from increasing loads.

Conducted studies and observations of existing buildings [4] have shown that sandwich panels have been made and assembled poorly. However, the assessed precast concrete was generally airtight, excluding sporadic cases, and the depth of the carbonation of concrete in façade panels did not exceed $5 \mathrm{~mm}$. In terms of sustainability, the working conditions of the plates are good, as the structural layer of the boards is not directly affected by atmospheric factors. From the outside of the building, it contacts with the insulating material, which is usually dry. In the examined buildings, it was found that mineral wool and styrofoam were dry or only slightly damp. After the winter-spring season, the maximum moisture content of mineral wool did not exceed $1.5-2.0 \%$, which indicated that the working conditions of plain steel hangers were more favorable than initially estimated. Occasional pitting corrosion, e.g. after 8 years of operation, pitting was $0.2 \mathrm{~mm}$ deep and did not significantly reduce the cross-section of the hangers.

The durability of a well-executed construction layer is expected to be over 100 years. The warming layer is generally thinner than required, which is the result of the insufficient density of the products used for warming and their compression during plate production. As a result, the walls are frosted and dampened. The elements that are important for the safety of the whole building, and therefore its life expectancy, are all kinds of joints, especially when they are not made of suitable materials.

The assessment of the technical condition and identification of damaged components [5] of panel buildings have revealed many attempts to repair the defects in joints. However, many repairs have been made incorrectly. In many cases lack of knowledge regarding the issues related to the construction of the discussed panel structures and failure to carry out more accurate analyzes caused fundamental technical errors. Movements in the joints of panel elements that constitute the façade of a building often negatively affect thermal insulation (moisture). As a result of the neglect, there were economic losses due to the need for further repairs or increased expenditures on current repairs. 
Strengthening and repair works in buildings erected using the industrialized method, in most cases have been executed without prior investigations, morphology of existing scratches and defects [6]. ETICS insulation layers are usually made in the standard way, without any additional work to remove the cause of the cracks and damage. Covered façade of the walls does not allow for the control of the state of important structural façade wall elements.

Investigations conducted in buildings with visible textured façade layer [7] in many Polish cities showed: the overvalued concrete thickness in the façade layer, the incorrect position of the hangers, and incorrect anchoring of the hangers. The steel of the built-in hangers (except H13N4G9 steel) did not meet the technical requirements, contained in the COBPBO Manual (technical guidelines for this type of buildings). In the analyzed cases, there were no corrosion defects of the hangers affecting the safety of the structural part of the multi-layer walls.

\section{Results of technical inspections in years 2005-06 and 2016-17 in Warsaw}

In 2005-06 95 buildings in Warsaw were inspected [8,9], and in 2016-17 110 buildings were examined. Data regarding large-block and large-panel dwellings and mixed technology (using prefabricated small-size elements and large-size prefabricated roof panels) was collected in representative quantities and quality. Buildings were chosen in terms of representativeness, so they are good examples of all the buildings in the settlements from which they are derived. Conclusions from the investigated buildings may be extrapolated to at least a three-fold higher number of buildings.

Few buildings in Warsaw made of prefabricated elements remain non-insulated. Out of the 110 buildings evaluated, 15 buildings have already been insulated twice (in the 2005-06 inspections, two buildings were already insulated twice, and one had double-insulated gable walls). Further layers have been added to the initial thermal insulation to achieve greater thermal energy savings. Some of the buildings were initially insulated only on the gable walls (without windows), and later, during the addition of insulation on the remaining walls, an additional layer was made on the first.

Another 21 buildings have been insulated twice, but the insulation works concerned different parts of the façade. In the first stage, only the gable walls (without windows) were insulated, because the unit cost was the lowest, and, as a result, the thermal conditions of the walls with the greatest frost penetration problems were corrected. Other walls, with windows, were warmed with radiators typically placed under the windows. In the case of 59 buildings, works covering the entire building or only gable walls were made once. The remaining 15 buildings have not had any insulation work done so far. The majority of them are buildings that were put into use in the 1990s. As they were built from upgraded system prefabricated materials, they are characterized by better insulation of exterior walls and roofs.

In addition, it has been found that not-isulated buildings are characterized by a relatively good quality of prefabricated materials, and the cases of leakage occur sporadically, between adjacent plates rather than in many plates. The frost's penetrations were present in few corners of examined buildings. The buildings were relatively new, and the façades are not technically problematic (Figure 3), so up to now, the co-operatives managing these buildings have not considered the insulation works economically and technically feasible. 


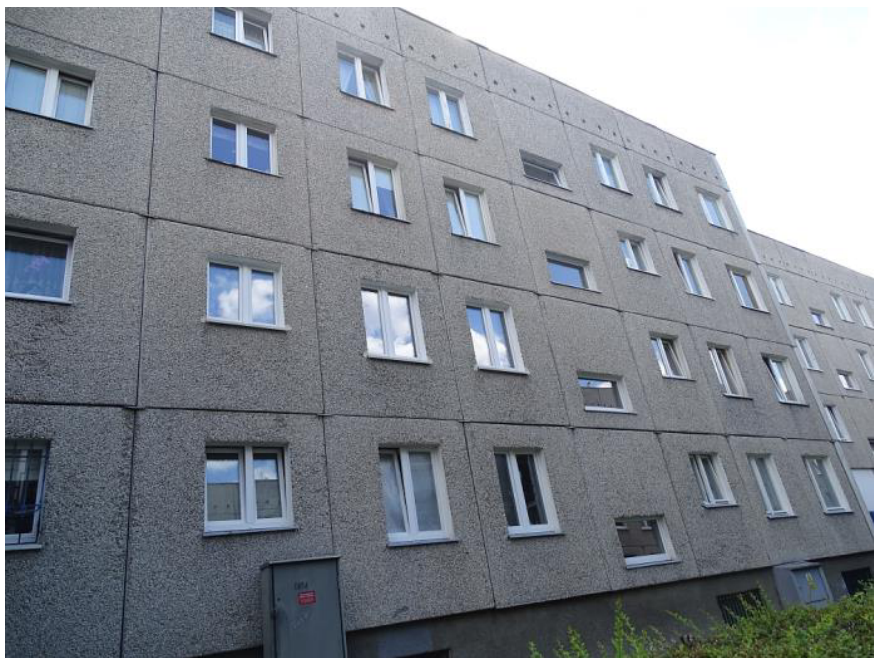

Fig. 3. Elevation of a non-insulated large-panel building (photo by Piotr Knyziak, 2016)

In 104 out of the 110 assessed buildings, the reinforcement of joints in laminated cladding boards was not performed. In some of the buildings in these settlements, the earlier versions of thermal insulation (heavy-dry or light-dry) were dismantled and the buildings were re-insulated using ETICS method. In three buildings located in the analyzed areas (not only the evaluated buildings), there were cases of wind rupture on the large façade surfaces (Figure 4). None of the failures observed in the ETICS insulation systems caused the failure of the structures of the sandwich panels. In cases of gas explosions in flats in paneled buildings, there were plate damages only in the immediate vicinity of the explosion site. In the distant parts of the building, rupture of the interlayer hangers did not occur.

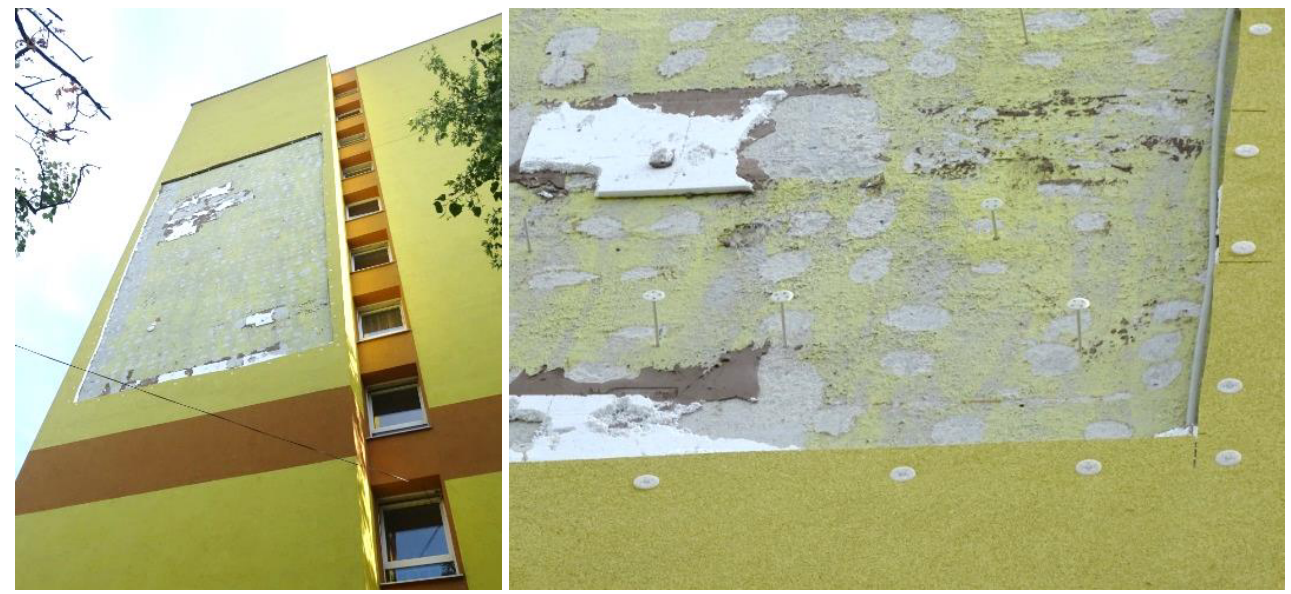

Fig. 4. ETICS system failures (photos by Piotr Knyziak, 2016)

Thermal insulation works, replacement of insulation, re-insulation, drilling of anchor holes to reinforce bonded joints in any of the buildings in the surveyed estates did not lead to the damage of the external façade panels. It should be emphasized that the process of drilling the holes designed for reinforcing anchors could have caused the vibrations and finally damages to the boards if they had already been weakened. 
The fact that reinforcing the joints of multipanel layers during buildings insulation is not commonly used is not the result of lack of solutions to apply. There are many options from different manufacturers. One of the co-authors of the present article has proposed his own patented solution to the problem of reinforcing the bonding of prefabricated slab layers (Figure 5).

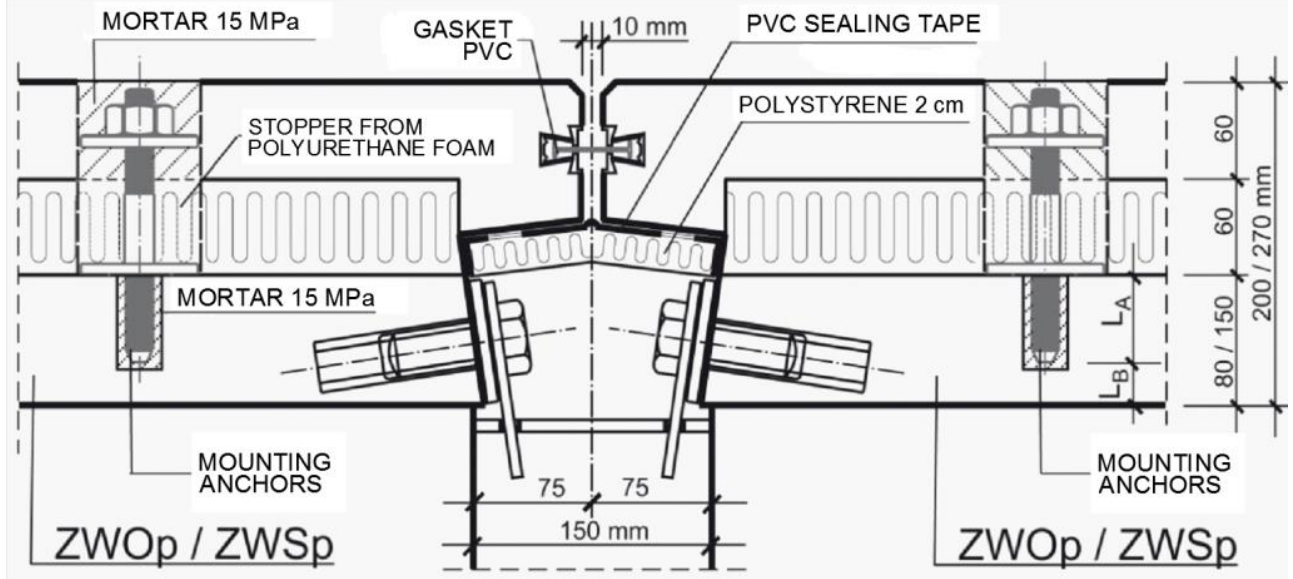

Fig. 5. The concept of connection reinforcing of prefabricated slabs (Janusz Krentowski)

Avoidance of reinforcing the layer connections is most often the result of significant costs (more than $10 \%$ of the value of the works) and executive issues that arise during the work. In one of the areas, after the initial experiences with the first reinforced building, the reinforcement of the joints was discontinued due to brittle concrete problems in the prefabricated buildings. During the drilling, there were extremely fragile breakings of concrete cones inside the apartments. A similar phenomenon can be sometimes observed in stairwells where residents made holes for dowels (Figure 6).

In addition, the limited number of tests regarding the condition of the connecting elements of the façade have brought positive results. The corrosion level of the fasteners was low, and the arrangement and number of fasteners allowed for the proper use of façade panels. The above conclusions were drawn on the basis of the openings made in the multilayer panels designed both for insulation projects and for the administrative decision of housing estates prior to the execution of thermal insulation. Due to the limited scope of research, its results cannot be the basis for general conclusions.
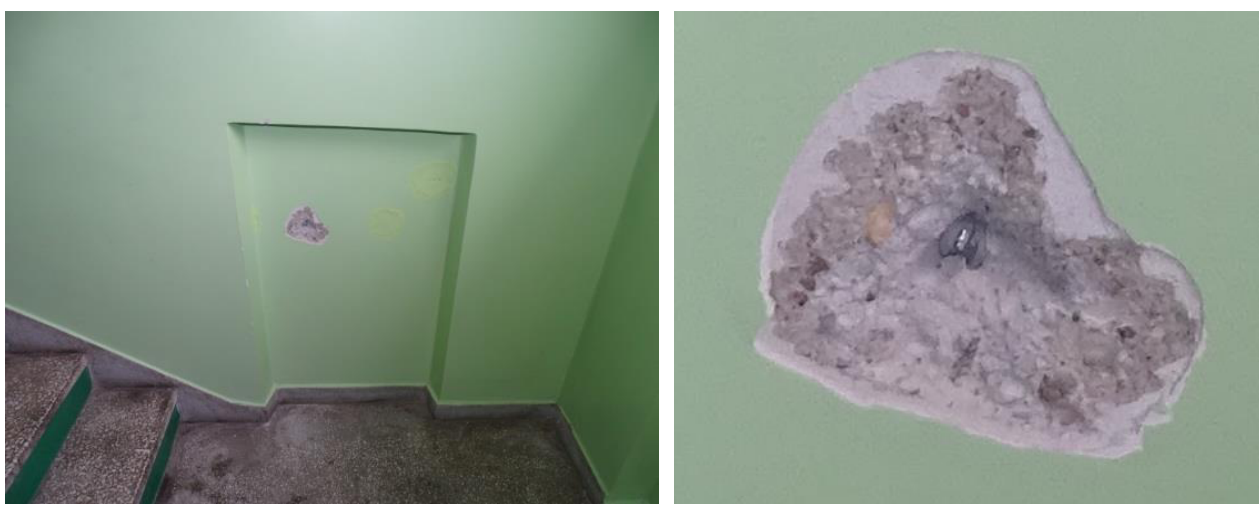

Fig. 6. Brittle breaking of concrete cones during drilling (photos by Piotr Knyziak, 2016) 
Important problems are connected with the surface damages of the ETICS insulations. They often embraced only a piece of façade surface, but are difficult to remove, because they are found on higher floors of buildings. The majority of the problems with ETICS systems are local, most often concern the oldest investments and are limited to painted surfaces. In some cases, defects are caused by poor execution process, non-compliance with the manufacturers' recommendations of ETICS system. Individual holes have been found, resulting in the insects and birds nesting.

The basic conclusion of the investigations, referring to the aforementioned research conducted in Gliwice [3], is the observation that in both technical inspections no visible deformation of the textured façade panels was noted. During the 2005-06 survey, many of the buildings were still not insulated and the state of the façade layer could be seen directly.

In 2016-17 surveys, the symptoms of incorrect operation of the ETICS system included deformation of the surface layer, scorching of the plaster in the outlines of styrofoam boards (excessive moisture transfer in the partition), unusual fractures (many plaster cracks due to incorrect execution or passes of time). The remark concerns not only the investigated 110 buildings, but also many neighboring buildings.

A well-made and preserved insulation layer on the façade wall significantly improves the operating conditions of façade boards and reduces the corrosion rate of interlayer fasteners. This is important for the aforementioned results [1], which speak of the layout mismatches and the type of steel grade. A significant improvement in the façade's technical condition is observed (Figure 7). The vast majority of buildings received a good rating indicating that the façade layers did not show any significant damage nor need repair.

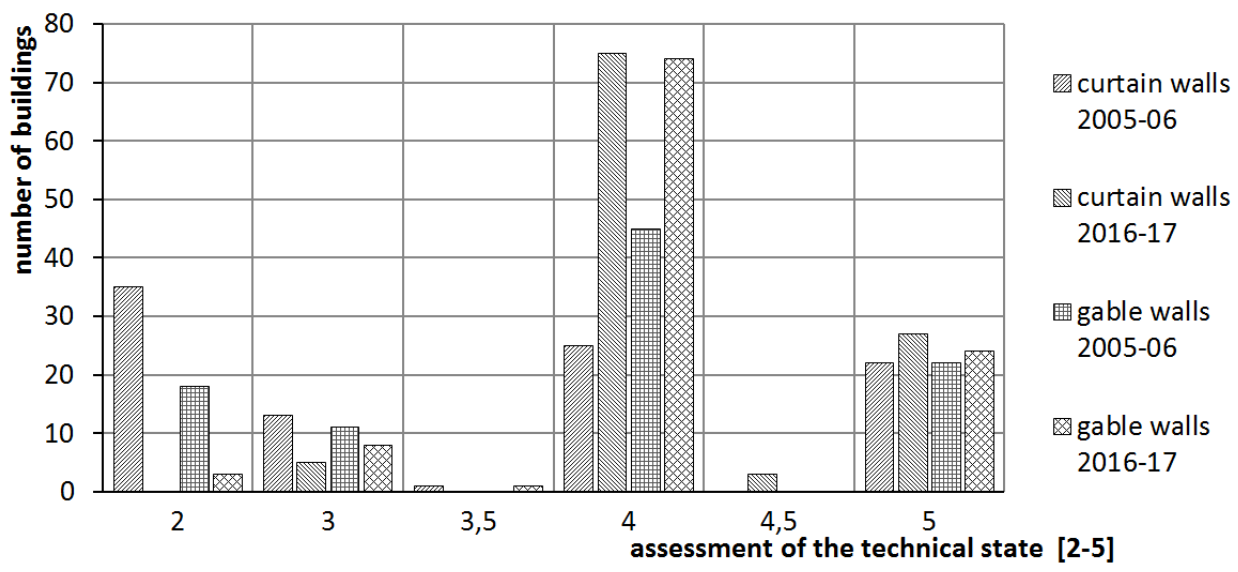

Fig. 7. Evaluation of the state of curtain and gable walls (data collected by Piotr Knyziak)

\section{Summary}

Inspections have shown good overall condition of the analysed buildings. Hasn't been noticed visible signs which would be point of any security risk. In buildings, however, it can be distinguishing installations or elements in visible unsatisfactory condition, waiting for repair or replacement.

Carried out authors studies confirm that the quality of the precast concrete residential buildings were built often did not as good as it should be. Often it was the result of imperfect technical knowledge but also often a hurry and not paying attention to the quality of the work. These studies also confirm the fact that the reliability of these residential 
buildings is high. There are no visible signs of progressive deterioration of the main structure. Elevations of buildings are properly maintained and the number of fully insulated and even twice insulated buildings increases.

Previous authors studies [1, 8-11] and the wide current work allow concluding that it is possible long-term safe use of prefabricated large-panel buildings. Durability of buildings properly exploited, who are under constant supervision is estimated as comparable to buildings made of monolithic technology.

Prior to the implementation phase of the extension up, enlargement or thermorenovation, it is important to define the method of elimination of the identified structural defects of the object. The fixing technology for additional thermal insulation and façade layers should take into account, in addition to the verification of the state of system connectors, the concept of reinforcement of the bonding and prefabrication zone of the prefabricated curtain wall and the preparation of the structural element for transferring additional load resulting from thermo-modernization or expansion.

\section{References}

1. J. Krentowski, R. Tribiłło, Przeg. Bud. 2, 34 (2008)

2. A. Ostańska, Przeg. Bud. 9, 68 (2011)

3. Z. Dzierżewicz, W. Starosolski, Systemy budownictwa wielkoptytowego w Polsce w latach 1970-1985 (Oficyna Wolters Kluwer Business, Warszawa, 2010)

4. Z. Ściślewski, Mat. Bud. 11, 3 (2004)

5. W. Ligęza, J. Dębowski, Konferencja Naukowo-Techniczna: Awarie Budowlane 2007, 741 (2007)

6. W. Ligęza, Budownictwo wielkoptytowe po latach. Wybrane problemy remontowe. Bud. i Arch. 3, 15 (2014)

7. M. Wójtowicz, Konferencja Naukowo-Techniczna: Awarie Budowlane 2011, 533 (2001)

8. P. Knyziak, Analiza stanu technicznego prefabrykowanych budynków mieszkalnych za pomoca sztucznych sieci neuronowych (PhD thesis. Warsaw University of Technology, Warsaw, 2007)

9. P. Knyziak, M. Witkowski, Inż. i Bud. 12, 639 (2007)

10. P. Knyziak, Procedia Engineering 91, 394 (2014)

11. P. Knyziak, Key Eng. Mat. 691, 420 (2016). 